\title{
The Effect of Network Relational Structure on Knowledge Diffusion Learning: An Empirical Study
}

\author{
https://doi.org/10.3991/ijet.v16i01.18229 \\ Zhang Renping \\ Economics and Management School of Wuhan University, Wuhan, China \\ Economics and Management School of LeShan Normal University, \\ Leshan, China \\ Zheng ShiYong \\ Guilin University of Electronic Technology, Guangxi, China \\ Qiu Ming $(\bowtie)$ \\ Guangxi College of Education, Nanning Guangxi, China \\ $229292710 @ q q \cdot c o m$ \\ Rizwan Ali \\ Wuhan Technology and Business University, Wuhan, China \\ Ubaldo Comite \\ University Giustino Fortunato, Benevento, Italy
}

\begin{abstract}
As social media has been popularized, users have shifted from the receiver of knowledge to the creator and communicator of knowledge. Besides, the relationship between users has become more sophisticated. In twoway and one-way networks, different network relationship structures formed between users have different impacts on the knowledge learning of information recipients. Some studies highlighted that knowledge, according to the different forms of knowledge generation and expression, can be split into explicit and tacit knowledge. Thus, in the network structure with different levels of relationship intensity, which type of knowledge can be spread and learned better? To answer this question, this study first uses second-hand data analysis. As revealed from the results of empirical research, under Weibo and WeChat, i.e., two different network structures, a variety of knowledge dissemination learning will have different effects. Then, by analyzing questionnaire data, the phenomenon and its internal mechanism are explained in accordance with the theory of regulatory focus.
\end{abstract}

Keywords-Network relational structure, explicit knowledge, tacit knowledge, regulatory focus theory 


\section{Introduction}

As fueled by the advancement of Internet technology, the way to achieve knowledge transmission and learning has developed significantly. In the conventional mass media age, the knowledge primarily originates from professionals, termed as OGC (Occupationally-generated Content) and PGC (Professionally-generated Content) [1]. People have access to the mentioned expertise in a vertical and one-way manner (e.g., books, radio and television). In the era of social media, the learners of knowledge can also become the creators and the disseminators of knowledge, and UGC (User Generated Content) acts as one of the main knowledge sources. People can spread and acquire knowledge through a horizontal, two-way way (e.g., Twitter, microblogs, WeChat and other social media) [2]. However, different social media also form different network structures. For instance, in social networks formed by microblogs and Twitter, fans are concerned with users, and one-way network structure relationship will be developed. In the social software (e.g., WeChat, QQ, and other types of social software), a friend is added to build a two-way network structure relationship. The one-way relationship reveals that the character of the user is obvious; one is the receiver of information, and the other acts as the sender of the information [3]. Besides, the user in the two-way relationship can act as the receiver of the information or the sending of the information. The asymmetry of the network structure leads to the inconsistent frequency of inter-user interaction in the network [4].

As revealed from the research, the relations are stronger among users with high interaction frequency, and those are weaker among users with low interaction frequency. It is highlighted that the same information/ knowledge can be fed back with the identical information/ knowledge in the users/ learners of different relationships [5]. It is therefore revealed that when the receiver faces different network structures, the information and the way of the transfer should be adjusted, so the acceptance rate of the information can be optimized. Accordingly, given different network structure users, how to select the proper communication content (knowledge) to enhance the acceptance of the knowledge by the receiver (learner) should be urgently solved [6].

\section{Theory and Hypothesis}

\subsection{Knowledge classification}

Knowledge refers to the deep processing of information. Michael Polanyi (1996) divided knowledge into explicit knowledge (Articulated Knowledge) and tacit knowledge (Tacit Knowledgeable). Explicit knowledge refers to the knowledge with high clarity, which can be encoded and formally described (Zhang Jianhua, 2010). It exists in the form of texts, pictures, achievements and patented inventions, and it is easy to display and transmit (Nonaka.1995). Tacit knowledge refers to the knowledge stored in the mind of the knowledge subject, which is the accumulation of long-term experience, whereas it has not yet been compiled. Its clarity is relatively low, it is hard to encode and formally describe (zhang,2010). It is private, complex, exclusive of the 
knowledge subject, and the sharing of tacit knowledge requires more efforts and costs [7].

Knowledge sharing is the participation in knowledge transactions between users. Bostrom (1989) defined knowledge sharing as a knowledge exchange between members within an organization out of mutual respect and trust. Huber extended the scope of knowledge sharing participants to groups within the organization. Gunnar (1994) considered that knowledge is constantly transferred out through the sharing process between individuals, teams, and organizations. With the change of users' demand for knowledge, the identity of knowledge demanders and providers will be altered [8].

\subsection{Classification of network relationships}

The network relationship in social network primarily refers to some types of connection developed between two network nodes (e.g., the friend relationship between two people, the transaction relationship between two enterprises, as well as the trade relationship between two countries) [9]. According to the properties of the network, the network can be classified into different types. For instance, according to the directivity of the network relationship, the network can be split into directed network (one-way network) and undirected network (two-way network). Under a two-way network, user A to user B and user B to user A are the identical relationship; under a one-way network, user A to user B and user B to user A are considered different relationships, which are the most obvious in Weibo [10]. To follow Big V, you can follow it; however, Big V does not necessarily follow you. In a two-way network, for the convenience of two-way interaction, acquaintances commonly use a two-way network for communication. In one-way networks, for the diversity of information sources, information is usually received between strangers. Accordingly, two-way and oneway networks can be considered a strong relationship network between acquaintances and a weak relationship network between strangers [11].

\subsection{Network relationship and knowledge dissemination}

At present, based on the investigation of various online social network interaction platforms, it is found that the knowledge sharing between network interaction subjects involves a variety of knowledge forms, primarily including text, picture, video and other explicit knowledge sharing as the main body, while for the experience of strong personal perception of ownership, skills and other tacit knowledge exchange and sharing willingness is restricted by many factors. (Sun, 2019) Jin Hui considered that tacit knowledge sharing among interactive subjects in social organizations is based on the interaction between ownership and self-efficacy perceived by individual holders of knowledge, i.e., individual holders of knowledge feel the knowledge they own (in particular the tacit knowledge with invisible characteristics), which can be recognized by the acquirer of knowledge through communication, thus bringing a strong sense of self-efficacy [12]. Make them willing to share their tacit knowledge (Jin, 2013) with others without any return [13]. The explicit knowledge is easier to receive and under- 
stand for its manifestation and complexity, so it is easier to propagate and learn in weak relational networks.

Therefore, this study puts forward the following assumptions:

$\mathrm{H} 1$ (a) : In the strong-relational social network, the user is more willing to share tacit knowledge ;

$\mathrm{H} 1$ (b) : In the weak-relational social network, the user is more willing to share explicit knowledge.

\section{$2.4 \quad$ Regulatory focus theory}

To achieve a specific goal, individuals try to change or control their own thoughts and reactions, a process called self-regulating (Geers, Weiland, Kosbab, Landry, \& Helfer, 2005) [14]. The theory of regulatory focus distinguishes two different ways or tendencies of self-regulation-promoting targeted (promotion focus) and preventing targeted (prevention focus). Some studies have suggested that regulating orientation can affect the persuasive effect of advertising. The researchers found that persuasion had the best effect when the framework of persuasive information complies with its regulatory orientation [15]. In other words, the information of the income framework is more persuasive when it is expressed in the way of promoting orientation, while the information of the loss framework is more persuasive when the information of the loss framework is expressed in the way of preventive orientation (Lee \& Aaker,2004).

In addition, the researchers also found that regulatory focus theory can also affect the persuasive effect by activating consumer persuasion knowledge (persuasion knowledge) [16]. Due to the alert strategic tendency of preventive orientation, it is more sensitive to the operational intention of the merchant and lower to the evaluation of the brand (Kirmani, \& Zhu,2007) than to promote the orientation. Therefore, the following assumptions are proposed in this study:

$\mathrm{H} 2$ (a) : in the strong-relational social network, Promotion focused opportunities trigger users to share tacit knowledge;

$\mathrm{H} 2$ (b) : in the weak-relational social network, Defense focused opportunities trigger users to share explicit knowledge.

The research model is shown in the following figure:

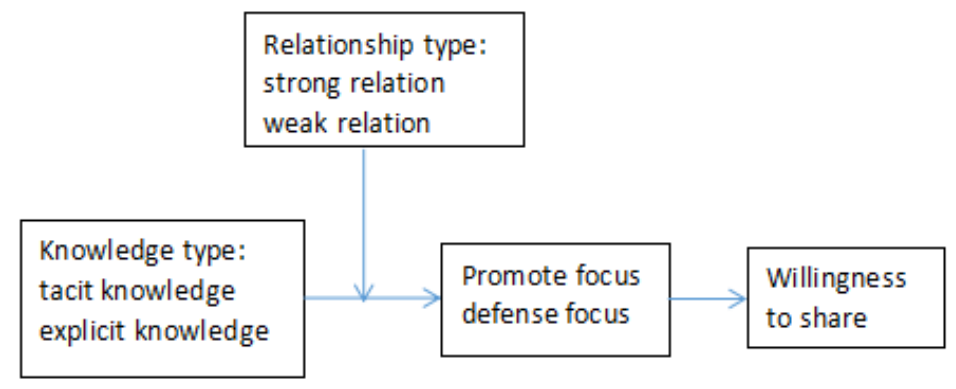

Fig. 1. The research model 


\section{Data and Experiments}

\subsection{Study 1}

Experiment 1 explored a variety of knowledge (explicit knowledge vs.). (tacit knowledge) (Michael Polanyi, 1996) the number of shares in social media. WeChat usually interacts with spouses, family members and good friends, thus representing a strong network, as reported by the China Internet Information Center (CNNIC) in 2017. The interaction objects in Weibo are usually partners, other acquaintances and strangers, so they represent the weak relationship network. Bruyn \& Lilien (2008) classified the strength of the relationship by spouse, family member, good friend, acquaintance and stranger [17]. Thus, this study considers Weibo as the representative of weak relationship social media and considers WeChat as the representative of robust relationship on social media. In this study, (1) the willingness to share explicit and tacit knowledge in social media is analyzed, as well as (2) the motivation triggered by explicit and tacit knowledge to arouse users to share effectively [18].

Data: A web crawler software is adopted to crawl information from 50 companies (e.g., clothes, cars, cleaning products) posted on their social media (Weibo and WeChat) from June 1 to December 31, 2018 (a total of 6389 articles). The crawling consists of the title of the article, the full text, the date of publication, the number of shares (Weibo), the number of readings (WeChat), the number of comments and the number of likes ${ }^{[19]}$.

Knowledge coding: In the experiment, dominant knowledge (4 items: Work reports, official documents, manuals, methodologies and models $=.92)$ and tacit knowledge (3 items: experience or know-how, know-where or know-whom, expertise $=.93$; Bock et al., 2005) are encoded by artificial coding $(\mathrm{N} \geq 20$, mean age $=21.8$ years). The coders are not aware of our research assumptions. To avoid fatigue, nearly 286 pieces of information is given randomly to each coder, and all coders will receive the title of each message, links to the full text of the article, as well as specific coding instructions. Each information is encoded by two independent encoders. The structural characteristics of each information are assessed by Likert scale $(1=$ not at all, $7=$ very). When the score is different, it is discussed and solved ${ }^{[20]}$. This study will give feedback to the coders their coding of a set of test information until they clearly understand the scoring criteria ${ }^{[21]}$. The reliability of all dimensions is significantly high (all > .70). The coding of each dimension is averaged (Table 1).

\begin{tabular}{|c|c|c|c|c|c|c|c|}
\hline & \multirow[b]{2}{*}{ M } & \multirow[b]{2}{*}{ SD } & \multicolumn{5}{|c|}{ Quantiles } \\
\hline & & & Min & $25 \%$ & Mdn & $75 \%$ & Max \\
\hline Explicit knowledge & 5.98 & 0.039 & 0.00 & 5.00 & 6.00 & 7.00 & 7.00 \\
\hline Tacit knowledge & 4.86 & 0.041 & 0.00 & 3.00 & 5.00 & 6.00 & 7.00 \\
\hline
\end{tabular}

Fig. 2. Explicit / tacit knowledge coding 
Control variables: As discussed above, external factors different from explicit knowledge and tacit knowledge may affect knowledge sharing. Therefore, the mentioned factors in the analysis are rigorously controlled ${ }^{[22]}$.

Vividness: The vividness of the content is controlled, as achieved by covering animations, colors, or pictures (Dreze and Hussherr 2003 / Fortin and Dholakia 2005 / Goodrich 2011). Virtual variables are created to control the vividness of published information ${ }^{[23]}$.

Interactivity: Because interactive content is more likely to be shared (e.g., being asked to do something to win prizes) ${ }^{[24]}$. To control the interactivity in the content, indicator variables are created ${ }^{[25]}$.

Title length: The length of the title positively impacts the diffusion speed and breadth of knowledge (Zhang Jing, 2018), so the title length is added as the control variable ${ }^{[26]}$.

Message length and day dummies: The length of text information is controlled. Longer information may contain sufficient details. Date variables are also employed to control the day a message first appears online (weekend or weekday) ${ }^{[27]}$.

Brand category: Perception of brands can also trigger different emotions and drive different sharing behaviors (Kervyn et,al., 2012). Accordingly, brand categories are created to control users' brand image of explicit and tacit knowledge ${ }^{[28]}$.

Analysis strategy.: The knowledge sharing data collected in Weibo and WeChat are analyzed by one factor variance analysis, and then the logical regression analysis is conducted on the data captured in Weibo ${ }^{[29]}$.

Explicit knowledge VS. Tacit knowledge sharing: As suggested from the results, the sharing of explicit knowledge in weak relational social media (Weibo) is significantly higher than that in tacit knowledge $(\mathrm{M}$ dominance $=68.21$ vs. $\mathrm{M}$ tacit $=27.32$; $\mathrm{F} \leq 10.20, \mathrm{p} \leq .001$ in Weibo), and the sharing of tacit knowledge in strongly relational social media (WeChat) is significantly higher than that in dominant knowledge ( $\mathrm{M}$ tacit $=28136.58$ vs. $\mathrm{M}$ dominance $=7356.79, \mathrm{~F} \geq 38.18, \mathrm{p}<0.001)^{[30]}$. As indicated from the results of logical regression, explicit knowledge sharing is significantly higher than tacit knowledge in weak relational social media (Weibo). The results of variance analysis and logical regression (Table 2) are consistent with the hypothesis $\mathrm{H}$ 1 (a), H 1 (b)



Fig. 3. Dominant vs. The result of quantitative variance analysis of tacit knowledge forwarded in Weibo is (ANOVA). 


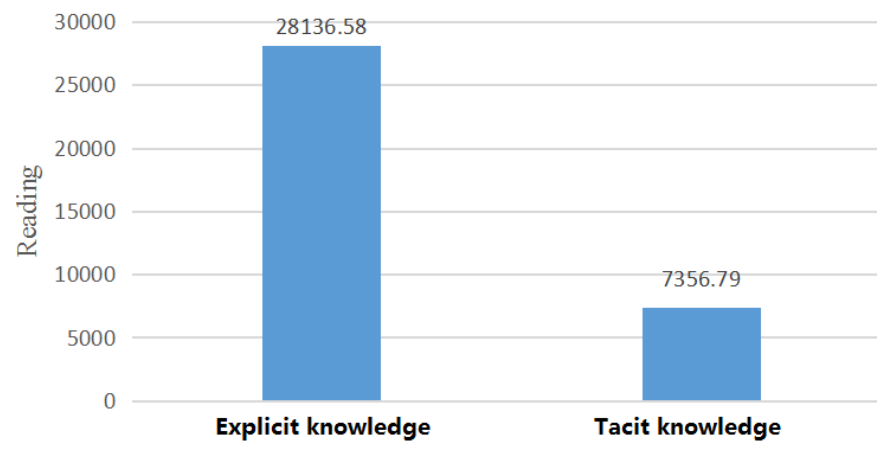

Fig. 4. Dominant vs. The results of quantitative variance analysis of tacit knowledge in WeChat (ANOVA)

\begin{tabular}{|c|c|c|c|c|c|c|}
\hline & $\begin{array}{l}\text { Knowledge } \\
\text { type }\end{array}$ & brand & $\begin{array}{l}\text { brand } \\
\text { *knowledge }\end{array}$ & star & $\begin{array}{l}\text { sales pro- } \\
\text { motion }\end{array}$ & $\begin{array}{l}\text { controlled } \\
\text { variable }\end{array}$ \\
\hline \multicolumn{7}{|l|}{$\begin{array}{l}\text { Knowledge } \\
\text { type : }\end{array}$} \\
\hline tacit knowledge & - & - & - & - & - & - \\
\hline $\begin{array}{l}\text { Explicit } \\
\text { knowledge }\end{array}$ & $\begin{array}{l}.28 * * * \\
(.05)\end{array}$ & $\begin{array}{l}.21^{* * *} \\
(.06) \\
\end{array}$ & $\begin{array}{l}.22 * * \\
(.08) \\
\end{array}$ & $\begin{array}{l}.28 * * \\
(.09)\end{array}$ & $\begin{array}{l}.28^{* *} \\
(.08) \\
\end{array}$ & $\begin{array}{l}.18^{*} \\
(.09)\end{array}$ \\
\hline \multicolumn{7}{|l|}{$\begin{array}{l}\text { controlled varia- } \\
\text { ble }\end{array}$} \\
\hline brand & - & $\begin{array}{l}1.23 * * * \\
(.07) \\
\end{array}$ & $\begin{array}{l}1.21^{* * *} \\
(.09)\end{array}$ & $\begin{array}{l}1.10^{* * *} \\
(.09)\end{array}$ & $\begin{array}{l}1.15^{* * *} \\
(.09) \\
\end{array}$ & $\begin{array}{l}.87 * * * \\
(.10)\end{array}$ \\
\hline $\begin{array}{l}\text { brand } \\
\text { *knowledge }^{\text {know }}\end{array}$ & - & - & $\begin{array}{l}.04 \\
(.12)\end{array}$ & $\begin{array}{l}.00 \\
(.12)\end{array}$ & $\begin{array}{l}.03 \\
(.13)\end{array}$ & $\begin{array}{l}.12 \\
(.14)\end{array}$ \\
\hline star & - & - & - & $\begin{array}{l}1.45^{* * *} \\
(.12)\end{array}$ & $\begin{array}{l}1.26^{* * * *} \\
(.12)\end{array}$ & $\begin{array}{l}1.23^{* * *} \\
(.14)\end{array}$ \\
\hline sales promotion & - & - & - & - & $\begin{array}{l}1.05^{* * *} \\
(.15)\end{array}$ & $\begin{array}{l}1.38^{* * *} \\
(.17)\end{array}$ \\
\hline vitality & - & - & - & - & - & $\begin{array}{l}1.18^{* * *} \\
(.08)\end{array}$ \\
\hline reciprocity & - & - & - & - & - & $\begin{array}{l}-.86 * * * \\
(.08)\end{array}$ \\
\hline Title length & - & - & - & - & - & $\begin{array}{l}.00^{* *} \\
(.00)\end{array}$ \\
\hline $\begin{array}{l}\text { contention } \\
\text { length }\end{array}$ & - & - & - & - & - & $\begin{array}{l}.00^{* *} \\
(.00) \\
\end{array}$ \\
\hline weekday & - & - & - & - & - & $\begin{array}{l}.24 * \\
(.09) \\
\end{array}$ \\
\hline Observations & 5385 & 5385 & 5385 & 5385 & 5385 & 5385 \\
\hline NagelkerkeR2 & .01 & .12 & .12 & .16 & .17 & .26 \\
\hline $\begin{array}{l}\text { Log-pseudo- } \\
\text { likelihood }\end{array}$ & 7266.37 & 6238.28 & 6236.36 & 6064.31 & 6007.26 & 5483.23 \\
\hline
\end{tabular}

Fig. 5. A likelihood of being shared as a function of its knowledge type 
Dummy variables: Type of knowledge (tacit knowledge $=0$, explicit knowledge $=$ 1 ), Brand type (tacit knowledge $=0$, explicit knowledge $=1$ ), date (Monday-Friday $=$ 0 , rest day $=1)$. $* * * \mathrm{P}<.001$. $* * \mathrm{P}<.01$. $* \mathrm{P}<.05$

Discussion of study 1: According to the results of the analysis of the content published on Weibo and WeChat for seven months ${ }^{[31]}$, explicit knowledge is easier to share than tacit knowledge in weak relational social media (Weibo), and tacit knowledge is easier to share than explicit knowledge in strong-relational social media (WeChat). These findings are consistent with our hypothesis of how social media affects explicit knowledge and tacit knowledge sharing willingness, H 1 (a), H 1 (b).

\subsection{Study 2}

To further verify the causality between independent variables and dependent variables in the model, we designed the second experimental, filed experiment. In this study, it is assumed that a variety of knowledge sharing will trigger different motivations of users in social media with different strong and weak relations: in weak relational social media, the sharing of explicit knowledge will induce users' defense focus motivation and strengthen their willingness to share; in strong-relational social media, the sharing of tacit knowledge will stimulate users to boost focus motivation and strengthen their willingness to share ${ }^{[32]}$.

Method: The researchers select 180 subjects (Mage=27.75 years, SD=3.26; 106 women) from a daily necessities company ${ }^{[33]}$. The subjects having received a random message (tacit or explicit knowledge) on their social media WeChat or Weibo and are asked to indicate whether they are willing to share it. Finally, the subjects should complete a questionnaire online. To verify the assumptions in the model, 2 (explicit knowledge vs.) is adopted in the experiment. Tacit knowledge) 2 (weak relational vs.) Strong relationship) experimental design between groups ${ }^{[34]}$.

In the experiment, the type of knowledge is manipulated into explicit knowledge and tacit knowledge. Before the formal experiment, the pre-experiment is performed, and 180 subjects participate in the pre-experiment to ensure the effectiveness of knowledge manipulation. The researchers show the subjects a piece of information related to knowledge and ask them to score the information according to the following dimensions, explicit knowledge (4 items: Work reports, official documents, manuals, methodologies and models =.92) and tacit knowledge (3 items: experience or knowhow, know-where or know-whom, expertise=.93) $(1=$ not at all, 7 = very $)$. In accordance with the experimental expectations, the manipulation score of explicit knowledge is significantly higher than that of tacit knowledge ( $\mathrm{M}$ explicit knowledge $=5.02$ vs. $\mathrm{M}$ tacit knowledge $=3.23 ; \mathrm{F} \geq 42.345, \mathrm{p}<0.001$ ), and the manipulation score of tacit knowledge is significantly higher than that of dominant knowledge ( $\mathrm{M}$ tacit knowledge $=4.56$ vs. $\mathrm{M}$ explicit knowledge $=3.58 ; \mathrm{F} \geq 10.68, \mathrm{p} \leq 0.001)$ [35].

Procedure: After the pre-experiment is completed, the subjects are randomly assigned to one of the four operating groups. After seeing manipulated information on their social media Weibo or WeChat, the subjects are asked to complete the questionnaire online. Lockwood P \& Jordan C H. (2002) is employed to measure userregulated focus motivation in social media. There are 18 items in the scale, including 
9 items for promoting focus and 9 items for defense focus, both of which had high reliability ${ }^{[36]}$.

Results: Similar to the results in experiment 1, the willingness to share explicit knowledge in weak relational social media is significantly higher than that in tacit knowledge $(\mathrm{M}$ explicit knowledge $=4.78$ vs. $\mathrm{M}$ tacit knowledge $=2.89 ; \mathrm{F} \geq 10.16, \mathrm{p}$ $\leq 0.001$ ). In strong-relational social media, the intension to share tacit knowledge is significantly higher than that in dominant knowledge ( $\mathrm{M}$ tacit knowledge $=4.87 \mathrm{vs}$. $\mathrm{M}$ dominant knowledge $=3.01 ; \mathrm{F} \leq 16.39, \mathrm{p}<0.001)$. The results show that the major effect of the model is significant.

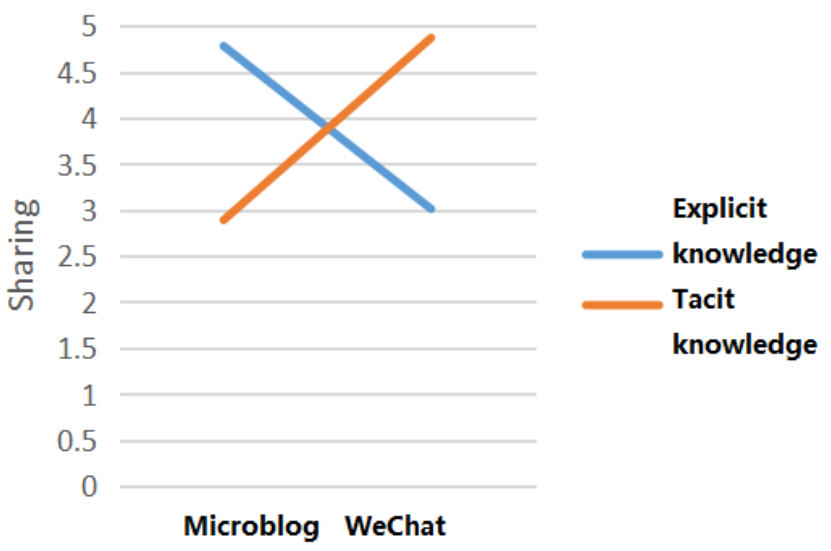

Fig. 6. main effect analysis diagram of the model

Mediation analysis: Based on the description in the model diagram, the motivation of promoting focus is the intermediary of tacit knowledge sharing in strongrelational social media, while defensive focusing is the intermediary of explicit knowledge sharing in weak relational social media ${ }^{[37]}$. To verify the assumptions in the model, the model between partial mediation and complete mediation are verified and compared. Under slight direct effect and obvious indirect effect, the model will be a complete intermediary; under both obvious direct effect and the indirect effect, the model will be a partial intermediary. The coefficients of indirect effects and mediation types are estimated in Table 3 and 4. The results show that the explicit knowledge of defense focus motivation $(97.5 \%$ confidence interval $(\mathrm{CI})=(.93,5.99)$ is shared in weak relational social media, and the dominant knowledge is promoted to be shared in strong-relational social media $\left(97.5 \%\right.$ confidence interval $(\mathrm{CI})=(.35,2.65)^{[38]}$. Two simple regression analyses show that the willingness to share a variety of knowledge in social media reveal the motivation to promote focus $(\mathrm{B} \leq .81, \mathrm{t} \leq 2.268, \mathrm{p}=.02)$ and defense motivation ( $\mathrm{B} / 53, \mathrm{t} \leq 2.53, \mathrm{p}=.01$ ). Second, the regression of knowledge types and two motivations show that defense focus motivation significantly predicts the number of explicit knowledge sharing $(\mathrm{B} \leq 61, \mathrm{t} \leq 5.308, \mathrm{p} \leq .000)$ in weak relational social media (Weibo), which supported the number of tacit knowledge sharing, and the results supported $\mathrm{H} 2 \mathrm{a}^{\left[{ }^{[3]}\right.}$. The results show that the number of explic- 
it knowledge sharing in weak relational social media (Weibo) is significantly higher than that in tacit knowledge sharing. Promoting focus motivation significantly estimates that the number of tacit knowledge sharing $(B \leq 95, t=19.81, p \leq .000)$ in weak relational social media (WeChat) is significantly higher than that of explicit knowledge sharing, which supports H2B (Fig. 4).

\begin{tabular}{|c|c|c|c|c|c|c|c|c|c|c|c|}
\hline & \multicolumn{2}{|c|}{$\begin{array}{l}\text { Model } 1 \\
\text { Sharing }\end{array}$} & \multicolumn{2}{|c|}{$\begin{array}{l}\text { Model 2 } \\
\text { Sharing } \\
\end{array}$} & \multicolumn{2}{|c|}{$\begin{array}{l}\text { Model 3 } \\
\text { prevention }\end{array}$} & \multicolumn{2}{|c|}{$\begin{array}{l}\text { Model } 4 \\
\text { promotion }\end{array}$} & \multicolumn{3}{|l|}{$\begin{array}{l}\text { Model 5 } \\
\text { Sharing } \\
\end{array}$} \\
\hline & $\beta$ & Wals & $\beta$ & Wals & $\beta$ & $\mathrm{t}$ & $\beta$ & $\mathrm{t}$ & $\beta$ & Wals & $\begin{array}{l}95 \% \text { confi- } \\
\text { dence inter- } \\
\text { val (CI) }\end{array}$ \\
\hline $\begin{array}{l}\text { Explicit } \\
\text { knowledge }\end{array}$ & .16 & .98 & -.15 & .98 & .17 & .37 & .09 & .82 & -.28 & 1.71 & $(-1.38, .06)$ \\
\hline $\begin{array}{l}\text { Explicit } \\
\text { knowledge } \\
* \quad \text { relationship } \\
\text { intensity } \\
\end{array}$ & - & - & $\begin{array}{l}.50^{* *} \\
*\end{array}$ & 22.28 & $\begin{array}{l}.18 * * \\
*\end{array}$ & 3.7 & .00 & .02 & $.49 * *$ & 9.16 & $(.25,1.39)$ \\
\hline Defense focus & - & - & - & - & - & - & - & - & $1.47^{* * *}$ & 15.11 & $(.96,6.97)$ \\
\hline Promote focus & - & - & - & - & - & - & - & - & .10 & .17 & $(-.48,2.18)$ \\
\hline & \multicolumn{2}{|c|}{$\begin{array}{l}\text { Log-pseudo- } \\
\text { likelihood=202.76 }\end{array}$} & \multicolumn{2}{|c|}{$\begin{array}{l}\text { Log-pseudo- } \\
\text { likelihood=77.10 }\end{array}$} & \multicolumn{2}{|c|}{$\mathrm{R}^{2}=.18$} & \multicolumn{2}{|c|}{$\mathrm{R}^{2}=.02$} & \multicolumn{3}{|c|}{ Log-pseudo-likelihood= $=42.60$} \\
\hline
\end{tabular}

Fig. 7. Mediation of competence orientation ad sharing through motives to impression management as a function of content orientation

Strong relation $=0$, weak relation $=1$, explicit knowledge $=1$, tacit knowledge $=0 . * * * \mathrm{P}<.001, * * \mathrm{P}<.01$, * $\mathrm{P}<.05, \wedge \mathrm{P}<.10$

\begin{tabular}{|c|c|c|c|c|c|c|c|c|c|c|c|}
\hline & \multicolumn{2}{|c|}{$\begin{array}{l}\text { Model } 1 \\
\text { Sharing }\end{array}$} & \multicolumn{2}{|c|}{\begin{tabular}{|l|} 
Model 2 \\
Sharing \\
\end{tabular}} & \multicolumn{2}{|c|}{\begin{tabular}{|l|} 
Model 3 \\
preven- \\
tion \\
\end{tabular}} & \multicolumn{2}{|c|}{$\begin{array}{l}\text { Model } 4 \\
\text { promo- } \\
\text { tion }\end{array}$} & \multicolumn{3}{|c|}{$\begin{array}{l}\text { Model } 5 \\
\text { Sharing }\end{array}$} \\
\hline & $\beta$ & Wals & $\beta$ & Wals & $\beta$ & $\mathrm{t}$ & $\beta$ & $\mathrm{t}$ & $\beta$ & Wals & $\begin{array}{l}95 \% \text { confidence interval } \\
\text { (CI) }\end{array}$ \\
\hline Tacit knowledge & $\begin{array}{l}.38 \\
* *\end{array}$ & 10.61 & $\begin{array}{l}.66^{* *} \\
*\end{array}$ & $\begin{array}{l}12.5 \\
8\end{array}$ & \begin{tabular}{|l|}
.1 \\
0
\end{tabular} & $\begin{array}{l}1.4 \\
2\end{array}$ & $\begin{array}{l}.28^{*} \\
* *\end{array}$ & $\begin{array}{l}4.3 \\
2\end{array}$ & $.35^{*}$ & $\begin{array}{l}4.0 \\
9\end{array}$ & $(-.01,1.06)$ \\
\hline $\begin{array}{l}\text { Tacit knowledge } * \\
\text { relationship intensity }\end{array}$ & - & - & $-35^{* *}$ & 7.27 & $\begin{array}{l}- \\
.0 \\
6 \\
\end{array}$ & $\begin{array}{l} \\
1.2 \\
3\end{array}$ & $\begin{array}{l}- \\
33^{*} \\
* *\end{array}$ & $\begin{array}{l}6.0 \\
8\end{array}$ & .00 & .00 & $(-.33, .56)$ \\
\hline Defense focus & - & - & - & - & - & - & - & - & $.66^{*}$ & \begin{tabular}{|l|}
5.9 \\
8
\end{tabular} & $(.22,1.70)$ \\
\hline \multirow[t]{2}{*}{ Promote focus } & - & - & - & - & - & - & - & - & $\begin{array}{l}.84 * \\
* * \\
\end{array}$ & $\begin{array}{l}10 . \\
18 \\
\end{array}$ & $(.34,2.64)$ \\
\hline & \multicolumn{2}{|c|}{$\begin{array}{l}\text { Log-pseudo- } \\
\text { likeli- } \\
\text { hood }=91.50\end{array}$} & \multicolumn{2}{|c|}{$\begin{array}{l}\text { Log-pseudo- } \\
\text { likeli- } \\
\text { hood=84.77 }\end{array}$} & \multicolumn{2}{|c|}{$\mathrm{R}^{2}=.04$} & \multicolumn{2}{|c|}{$\mathrm{R}^{2}=.33$} & \multicolumn{3}{|c|}{ Log-pseudo-likelihood=81.08 } \\
\hline
\end{tabular}

Fig. 8. Mediation of warmth orientation ad sharing through motives to social bonding as a function of content orientation

Strong relation $=0$, weak relation $=1$, explicit knowledge $=1$, tacit knowledge $=0 . * * * \mathrm{P}<.001, * * \mathrm{P}<.01$, $* \mathrm{P}<.05, \wedge \mathrm{P}<.10$ 


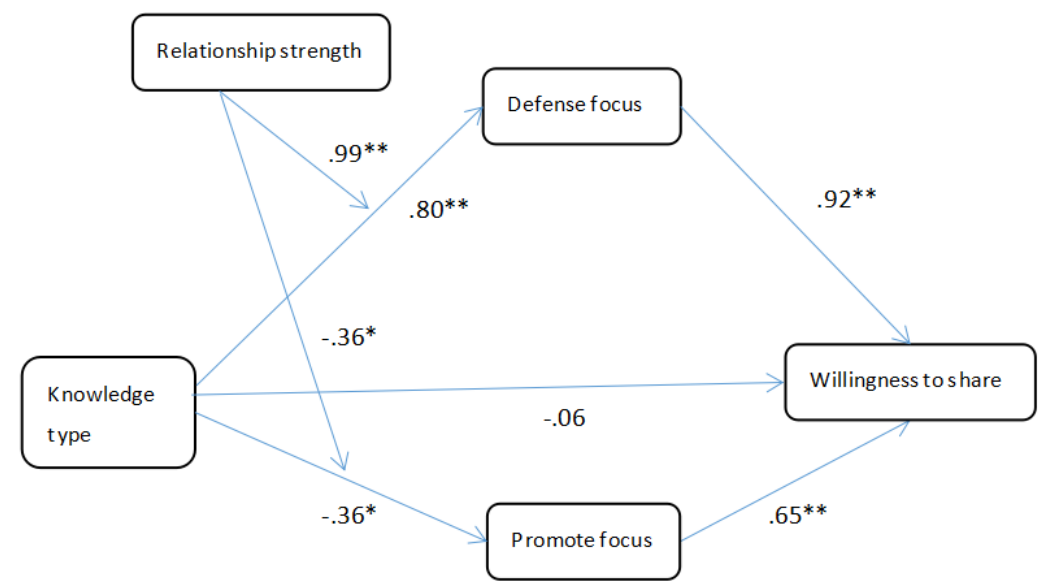

Fig. 9. Analysis diagram of intermediary effect

\section{$4 \quad$ Summary and Discussion}

Based on the review and summary of knowledge sharing, theory of regulatory focus and other relevant studies, given the second-hand data achieved in social media, this study proposes that explicit knowledge sharing and the tacit one has different motivations in different social media [40]. The theory of regulatory focus (Higgins E $\mathrm{T}, 1987$ ) considers that two states, i.e., the pursuit of ideal ultimate state (their own and others' expectations of it) and the ultimate state of responsibility (their own and others' responsibility for it); on that basis, two different tendencies of self-regulation are formed, i.e., promoting focusing and defensive focusing [41].

Differences are identified in behavioral motivation, pursuit of goals, action strategies, result response and emotional experience between the two types of selfregulating individuals. As revealed from the results, in weak relational social media (Weibo), defense focuses on consumers are inclined to share the rational experience of knowledge, so users become more willing to share explicit knowledge as motivated by defense focus. Besides, in strong-relational social media (WeChat), the emotional experience is promoted in which consumers are inclined to share knowledge, demonstrating that promoting focus motivation makes users more willing to share tacit knowledge. To cause wide sharing of relevant product knowledge in social media, enterprises should determine the relationship intensity in social media used by users and design explicit and tacit knowledge given different relational strengths to trigger users' defense and promote focus motivation, to promote knowledge sharing. Prospects for future research include:

First, the empirical research on the influencing factors of knowledge quality and utility should be strengthened. It has been found that the quantity and quality of knowledge have an important impact on consumer perceived ease of use and perceived usefulness and more significantly impact consumers who lack professional knowledge (Kees J, 2010). Knowledge quality is also related to the satisfaction of 
users' knowledge needs and the willingness to continue to share knowledge. If users in social media, especially core users, have gained profound knowledge and views in a certain aspect, the quality of content they share is often high; thus, considerable users will participate in knowledge sharing and transmission. Knowledge utility refers to the value and applicability of knowledge. H. L. Yang (2008) considered that individual perception of knowledge value is an important factor affecting knowledge sharing, so knowledge utility as a factor critically affecting the willingness to share in social media is worth further studying.

Second, social media users should be stimulated to create content. Enterprises publish knowledge content in their social media, stimulate users' online word-of-mouth by arousing users' emotional experience and rational cognition, i.e., users create content, and encourage users to share information about products, services, brands or events with others (Godes, D., Mayzlin, D., 2004). Hennig, T., Gwinner,K.P., etc., 2004), online word-of-mouth has inestimable propagation speed (Hennig, T., Gwinner,K.P.,2008), higher accessibility and more lasting influence (Goldsmithre,2006).

Third, the matching between knowledge and adjustment focus under product type adjustment. The adjustment matching theory proposed by Higgins states that when the adjustment focus tendency of an individual complies with the stimulation of the external environment, the individual will produce a higher degree of confirmation (Higgins E. T, 2000). Individuals who promote focus are more creative and fonder of changing things, and they also tend to receive highly innovative products; defensefocused individuals prefer stability and consistency and are extremely risk-sensitive, so they are inclined to be similar or even the same (Higgins E. T, 2012). Roy and Naidoo suggested that in decision-making, individuals who promote focus prefer buying search items, while defense-focused individuals are more likely to choose empirical goods (Roy R., 2017). In fact, Avnet and Higgins highlighted that because regulatory focus is the basic motivation orientation of individuals, any consumer will have (Avnet T, 2006). Thus, regulation focus should be an important explanation perspective to interpret the impact of knowledge on consumer differentiation under product type regulation.

\section{Acknowledgement}

This work is supported the following fund:

National natural science foundation : Research on panoramic and prescriptive marketing management and decision driven by big data in consumer market (NO:91746206); Omni Synchronous Marketing Paradigm in the Mobile Era: Tripartite Synchronous Interaction and Product-driven Integral Affect (NO:71672132).

2017 Guangxi education science 'ten-three-five' planning project: Based on zte's ICT education platform of fusion, work-integrated learning education training mode research (No,2017B107).

2018Guangxi Young and Middle-aged Teachers 'Achievement Project: Design and implementation of picking Robot based on Internet of things (No,2018KY0556). 
2018Guangxi higher Education Teaching Reform Project: Exploration of cultivating Mechanism of Teaching characteristics of Communication Engineering Specialty based on ICT Education platform of ZTE(No,2018JGB322).

2018Guangxi Vocational Education Teaching Reform Project: Reflections on the course setup of English majors in Private Vocational Colleges in Guangxi under Market demands Taking Guangxi Talent International College as an example (NO, GXGZJG2018A035)

2020Guangxi Young and Middle-aged Teachers' Achievement Project: No,2020KY80008).

2019BAGUI Scholar Program of Guangxi Zhuang Autonomous Region of China (No,201979)

Research Initiation Project of Ph.D., for GUET: Research on the Incentive Mechanism of Knowledge Sharing in Online Medical Community (No, US20001Y).

\section{References}

[1] Tsai W, Ghoshal S. Social Capital and Value Creation. (1998). An Empiri- cal Study of Intrafirm Networks, Academy of Management Jour- nal, vol.41, no.4, pp.464-467.

[2] Larson A. (1992). Network Syads in Entrepreneurial Settings: A Study of the Governance of Exchange Relationships, Administrative Science Quarterly, vol.37, no.1, pp.76-104. https://doi.org/10.2307/2393534

[3] Chiu C M, Hsu M H, Wang E T G. (2006). Understanding Knowledge Sha- ring in Virtual Communities: An Integration of Social Capital and Social Cognitive Theories, Decision Support Systems, vol.42, no.3, pp.1872-1888, 2006. https://doi.org/10.1016/j.dss.2006.04.0 $\underline{01}$

[4] Dobrzykowski D D, Tarafdar M. (2015). Understanding Information Ex- change in Healthcare Operations: Evidence from Hospitals and Pa- tients, Journal of Operations Management, no.36, pp.201-214. https://doi.org/10.1016/j.jom.2014.12.003

[5] Chang H H, Hsieh P H, Fu C S. (2016). The Mediating Role of Sense of Virtual Community, Online Information Review, vol.40, no.7, pp.882-899. https://doi.org/10.1108/ oir-09-2015-0304

[6] Zárraga C, Bonache J. (2003). Assessing the Team Environment for Knowledge Sharing: An Empirical Analysis, International Journal of Human Resource Management, vol.14, no.7, pp.1227-1245. https://doi.org/10.1080/0958519032000114282

[7] Nonaka I,Takeuchi H. (1995). The Knowledge-creating Company: How Japanese Companies Create and the Dynamics of Innovation, Oxford University Press, New York.

[8] Bostrom R P. (1989). Successful application of communication techniques to improve the systems development process, Information and Management, vol.16, no.2, pp.279-295. https://doi.org/10.1016/0378-7206(89)90005-0

[9] Huber G P. (2000). Organizational Learning, The Contributing processes and the literatures, Organization science, vol.11, no.5, pp.538-550.

[10] Gunnar H. (1994). A model of knowledge management and the N-form corporation, Strategy Management Journal, vol.15, no.15, pp.73-90.

[11] Hou Changhai. (2016). Analysis of China's online education market in 2015, Internet World, no.2, pp.85-88.

[12] Huang Wenzhi, Zhao Jing. (2016). Discussion on the development prospect of online education in the era of Internet +, China Adult Education, no.6, pp.138-140. 
[13] Dinah G. \& Daniel K. \& Isabel W. \& Jayne C. (2014). Training Needs Analysis: A Literature Review and Reappraisal, International Journal of Nursing Studies, vol.42, no.5, pp.110.

[14] Wu Xiaoqiong, Xing Yanfang. (2015). Analysis of the Development Path of Online Education, Journal of Zhangzhou Teachers College, no.1, pp.87-90.

[15] Chen Qilin, Bao Haobo. The history and current situation of online education development in China, Xueyuan, no.26, pp.184-185.

[16] Yang Wei, Yan Jin. (2016). Analysis of the Teaching Reform of Open Online CourseTaking L College as an Example, Value Engineering, vol.35, no.19, pp.207-209.

[17] Xiao Yuewen, Wang Mingyu. (2017). Talking about the status quo and development trend of online education, China Business Theory, no.18, pp.176-177.

[18] Earl L., Katz S. (2006). Leading Schools in a Data Rich World, Corwin Press, vol.23, no.2, pp.9-16.

[19] Zhang Junchao. (2014). Institutional Research and University Management in the Age of Big Data, Higher Education Research, no.1, pp.128.

[20] Chen Lei. (2017). Application of Big Data in Teachers' Online Education EnvironmentTaking Courses in Zhejiang Province as an Example, Continuing Education, vol.31, no.9, pp.7-11.

[21] Yang Xianmin, et al. (2014). Development Strategy and Path Choice of Wisdom Education in China, Modern Educational Technology, no.1, pp.14.

[22] Liu Bin, Zhang Wenlan. (2017). Research on the Influencing Factors and Structure of Online Course Learning Experience, Modern Educational Technology, vol.27, no.09, pp.107-113.

[23] Zheng Lei. (2014). Online Learning and Quality Assessment Research, Shenzhou, pp.14.

[24] Zhang Wei. (2011). Strategies for improving the participation of college students in online learning, Zhejiang Normal University. Zhejiang, Chian.

[25] Maclaughlin E J, Supernaw R B, Howard K A. (2004). Impact of distance learning using videoconferencing technology on student performance, American Journal of Pharmaceutical Education, vol.68, no.3, pp.1-6. https://doi.org/10.5688/aj680358

[26] Guan Jia, Li Qitao. (2014). Development Status, Trends and Experiences of Online Education in China, China Electro-chemical Education, no.08, pp.62-66.

[27] Sun Li, Cheng Yuxia. (2015). Research and Implementation of Online Education Learning Achievement Prediction in Big Data Era--Taking English as an Example of Undergraduate Public Courses, Open Education Research, no.3, pp.74-80.

[28] Kees J., Tangari A. H. (2010). The Impact of Regulatory Focus,Temporal Orientation, and Fit on Consumer Responses to Health-Related Advertising, Journal of Advertising, vol.39, no.1, pp.19-34. https://doi.org/10.2753/joa0091-3367390102

[29] Heng-Li Yang, Wu,T.C.T. (2008). Knowledge Sharing in an Organization-Share or Not, Technological Forecasting \& Social Change, vol.75, no.8, pp.1128-1156. https://doi.org/ 10.1016/j.techfore.2007.11.008

[30] Higgins E. T. (2012). Beyond Pleasure and Pain: How Motivation Works. London: Oxford University Press.

[31] Higgins E. T. (2000). Making a Good Decision: Value from Fit, American Psychologist, vol.55, no.11, pp.1217-1230. https://doi.org/10.1037/0003-066x.55.11.1217

[32] Roy R., Naidoo V. (2017). The Impact of Regulatory Focus and Word of Mouth Valence on Search and Experience Attribute Evaluation, European Journal of Marketing, vol.51, no.7/8, pp.1353-1373. https://doi.org/10.1108/ejm-06-2016-0367 
[33] Avnet T. Higgins E. T. (2006). How Regulatory Fit Affects Value in Consumer Choices and Opinions, Journal of Marketing Research, vol.43, no.1, pp.1-10. https://doi.org/10.15 09/jmkr.43.1.1

[34] Godes, D., Mayzlin, D. (2004). Using online conversations to study word-of-mouth communication, Marketing science, vol.23, no.4, pp.545-560. https://doi.org/10.1287/mk $\underline{\text { sc. } 1040.0071}$

[35] Hennig, T.T., Gwinner,K.P., Walsh, G. (2004). Electronic word-of-mouth via consumeropinion platforms: What motivates consumers to articulate themselves on the internet? Journal of interactive marketing, vol.18, no.1, pp.38-52. https://doi.org/10.1002/dir.10073

[36] Duan, W. J., Gu. B., Whinston, A. B. (2008). The dynamics of on- line word-of-mouth and product sales- an empirical investigation of the movie industry, Journal of retailing, vol.84, no.2, pp.233-242. https://doi.org/10.1016/j.jretai.2008.04.005

[37] Goldsmithre, Horowitzd. (2006). Measuring motivations for online opinion seeking, Journal of interactive advertising, vol.6, no.2, pp.1-16, 2006.

[38] He, H.; Li, S.; Hu, L.; Duarte, N.; Manta, O.; Yue, X.-G. (2019). Risk Factor Identification of Sustainable Guarantee Network Based on Logistic Regression Algorithm, Sustainability, no.11, pp.3525. https://doi.org/10.3390/su11133525

[39] Zheng, S.-Y., Jiang, S.-P., Yue, X.-G., Pu, R., Li, B.-Q. (2019). Application research of an innovative online education model in big data environment, International Journal of Emerging Technologies in Learning, vol.14, no.8, pp.125-138. https://doi.org/10.3991/ijet. $\underline{\mathrm{v} 14 \mathrm{i} 08.10404}$

[40] Verónica Díaz Quezada. (2020). Difficulties and Performance in Mathematics Competences: Solving Problems with Derivatives, International Journal of Engineering Pedagogy (iJEP), vol.10, no.4, pp.35-53. https://doi.org/10.3991/ijep.v10i4.12473

\section{Authors}

Zhang Renping (1982-), comes from leshan, Sichuan province. PhD student, associate professor, the main research direction for network marketing, consumer behavior. (e-mail: 20044841@qq.com).

Zheng Shiyong (1983-), comes from Guilin, Guangxi province. PhD student, senior engineer, the main research direction for network marketing, IOT. (e-mail: 229292710@qq.com).

Qiu Ming (1978-), come from Beiliu, Guangxi province. Master of Science, associate professor, the main research direction for Educational technology, Computer science and technology. (e-mail: 33044810@qq.com).

Rizwan Ali (1980-), comes from Lahore, Punjab province, Pakistan. Assistant Professor in Wuhan Technology and Business University, Wuhan, Hubei, China. The main research direction is digital marketing, brand relationship and word of mouth (Email: rizwan.ali@whu.edu.cn)

Ubaldo Comite, is a professor in University Giustino Fortunato, 82100 Benevento, Italy. ubaldo.comite@libero.it

Article submitted 2020-09-12. Resubmitted 2020-10-18. Final acceptance 2020-10-22. Final version published as submitted by the authors. 